\title{
Designing a New Multi-Echelon Multi-Period Closed- Loop Supply Chain Network by Forecasting Demand Using Time Series Model: A Genetic Algorithm
}

\section{Shahab Safaei}

Islamic Azad University of Firuzkuh: Islamic Azad University Foroozkooh Branch

Peiman Ghasemi ( $\square$ peiman.ghasemi@gutech.edu.om )

German University of Technology in Oman

\section{Fariba Goodarzian}

MIR Labs: Machine Intelligence Research Labs

\section{Mohsen Momenitabar}

North Dakota State University

\section{Research Article}

Keywords: Closed-loop supply chain network, Demand forecasting, Mathematical model, ARIMA time series model, Genetic algorithm.

Posted Date: January 3rd, 2022

DOI: https://doi.org/10.21203/rs.3.rs-1127415/v1

License: (9) This work is licensed under a Creative Commons Attribution 4.0 International License. Read Full License

Version of Record: A version of this preprint was published at Environmental Science and Pollution Research on March 4th, 2022. See the published version at https://doi.org/10.1007/s11356-022-19341-5. 


\title{
Designing a New Multi-Echelon Multi-Period Closed-Loop Supply Chain Network by Forecasting Demand Using Time Series Model: A Genetic
}

\section{Algorithm}

\author{
Shahab Safaei ${ }^{1}$, Peiman Ghasemi2 ${ }^{2}$, Fariba Goodarzian ${ }^{3}$, Mohsen Momenitabar ${ }^{4}$ \\ ${ }^{1}$ Department of Industrial Engineering, Faculty of Industrial Engineering, Firoozkooh \\ Branch, Islamic Azad University, Firoozkooh, Iran Email: Ksanan46@ yahoo.com \\ ${ }^{*}$ Department of Logistics, Tourism and Service Management, German University of Technology \\ in Oman (GUtech), Muscat, Oman, (Corresponding author), Email: \\ peiman.ghasemi@gutech.edu.om \\ ${ }^{3}$ Machine Intelligence Research Labs (MIR Labs), Scientific Network for Innovation and \\ Research Excellence, 11, 3rd Street NW, P.O. Box 2259. Auburn, Washington 98071, USA, \\ Email:Fariba.Goodarzian@mirlabs.org, \\ ${ }^{4}$ Department of Transportation, Logistics, and Finance, North Dakota State University (NDSU), \\ 58105-6050, USA, Email: Mohsen.momenitabar@ndsu.edu,
}

\begin{abstract}
:
In the closed-loop supply chain, demand plays a critical role. The flow of materials and commodities in the opposite direction of the normal chain is inevitable too. So, in this paper, a new multi-echelon multi-period closed-loop supply chain network is addressed to minimize the total costs of the network. The considered echelons include suppliers, manufacturers, distribution centers, customers, and recycling and recovery units of components in the proposed network. Also, a linear programming model considering factories' vehicles and rental cars of transportation companies is formulated for the proposed problem. Moreover, the products demand is predicted by Auto-Regressive Integrated Moving Average (ARIMA) time series model to decrease the amount of shortage may happens in the network. To solve the proposed model, GAMS software is used in small-sized problems and a genetic algorithm in large-sized problems is employed. Numerical results show that the proposed model is closer to the real situation and the proposed solution method is efficient. Accordingly, sensitivity analysis is performed on important parameters to show the performance of the proposed model.
\end{abstract}

Keywords: Closed-loop supply chain network, Demand forecasting, Mathematical model, ARIMA time series model, Genetic algorithm.

\section{Introduction}

The issue of designing the transportation network in the supply chain has attracted a lot of attention in today's competitive world (Chan et al. 2016). Providing better services by companies to satisfy 
customers, decreasing costs, and increase net profit is one of the consequences of this competition ( Xu et al. 2017). Supply chain network design is a strategic issue that helps to select the best combination of a set of facilities to achieve efficient and effective network (Almaraj and Trafalis, 2019). Designing a distribution network is one of the key issues in the design of the supply chain network, which offers an important potential factor to reduce costs and improve service quality (Margolis et al. 2017, Goodarzian et al. 2021a, Goodarzian et al. 2021b, Mosallanezhad et al. 2021). Therefore, the design of supply chain network plays an outstanding role in long-term strategic decision-making ( $\mathrm{Wu}$ et al. 2017). Also, researchers in recent years have paid more attention to the multi-product nature of such problems (Wang and Gunasekaran, 2017), in this research, modeling the design of transportation network in the supply chain and its solution by meta-heuristic methods are developed and discussed.

Over the past two decades, there has been tremendous global changes due to advances in technology, the globalization of markets and the new economic-political conditions (Ghasemi et al. 2017). Due to the growing number of competitors in the global class, organizations were forced to quickly improve intra-organizational processes to stay in the global competition. In the 1960s$70 \mathrm{~s}$, organizations tried to develop detailed market strategies that have mainly focused on satisfying customers (Mohtashami et al. 2020). They realized that robust engineering and design, and coherent production operations were the prerequisite for achieving market requirements and thus more market share. Therefore, designers were forced to incorporate the ideals and requirements of their customers into their product design, and in fact, they had to supply a product with the maximum possible level of quality, at minimum cost considering the customer's desired ideals (Hassanpour et al, 2019, Modibbo et al. 2019, Ali et al. 2021, Modibbo et al. 2021). In this research, a new mathematical model for optimizing the closed-loop supply chain, whose main objectives including determination of the optimal amount of products and components in each segment of the network, minimizing the total cost of the system, optimizing the amount of transportation in the entire system has been proposed. This research aims to design a closed-loop supply chain network includes suppliers, manufacturers, distribution centers and customers, collection and disassembly centers, product, and component recovery units, as well as a facility for destruction and burial of damaged and polluting components. 
64 Fig.1 has shown a closed-loop supply chain network of this study. Suppliers send components to 65 factories and factories produce products based on received demand from customers. The generated products are sent to distribution centers by factories' trucks or transportation companies in order

67 to be delivered to the customers. In order to increase the speed of transporting products to meet 68 the customers' needs without encountering bottlenecks and shortages of vehicles, the trucks of the 69 factories and the transportation companies have been used simultaneously. A few products are 70 returned by consumers and are gathered in the product collection centers. The collection center 71 divides the products into two parts including usable and unusable sections. Some after72 consumption products have not yet finished their lifetime can be reused again by some repairing. 73 They are sent to the product recovery centers from the product collection center to be recovered. 74 Then, these products are sent to distribution centers after recovery and repairs. Unusable products 75 are disassembled into components in disassembly centers. The components that are usable can be 76 reused after repairing by the repairing and recovery centers. But some unusable components should 77 be destroyed or buried. These types of components, such as chemical batteries, chips, various types 78 of chemicals and plastics, and various types of pollutants, are harmful to the environment, and they 79 take many years to be recovered. Therefore, these components have been considered as waste and 80 are gathered in destruction and burial centers for technological clearing. Because the capacity of 81 the recovery unit for components is limited, several recovery centers are needed. After the recovery 82 phase, the reconstructed components are taken to the warehouse section of the factories to be used 83 as new components. Due to the fact that the recovery and collection centers are limited, new 84 components are purchased from suppliers based on demand and the number of recovered 85 components. 


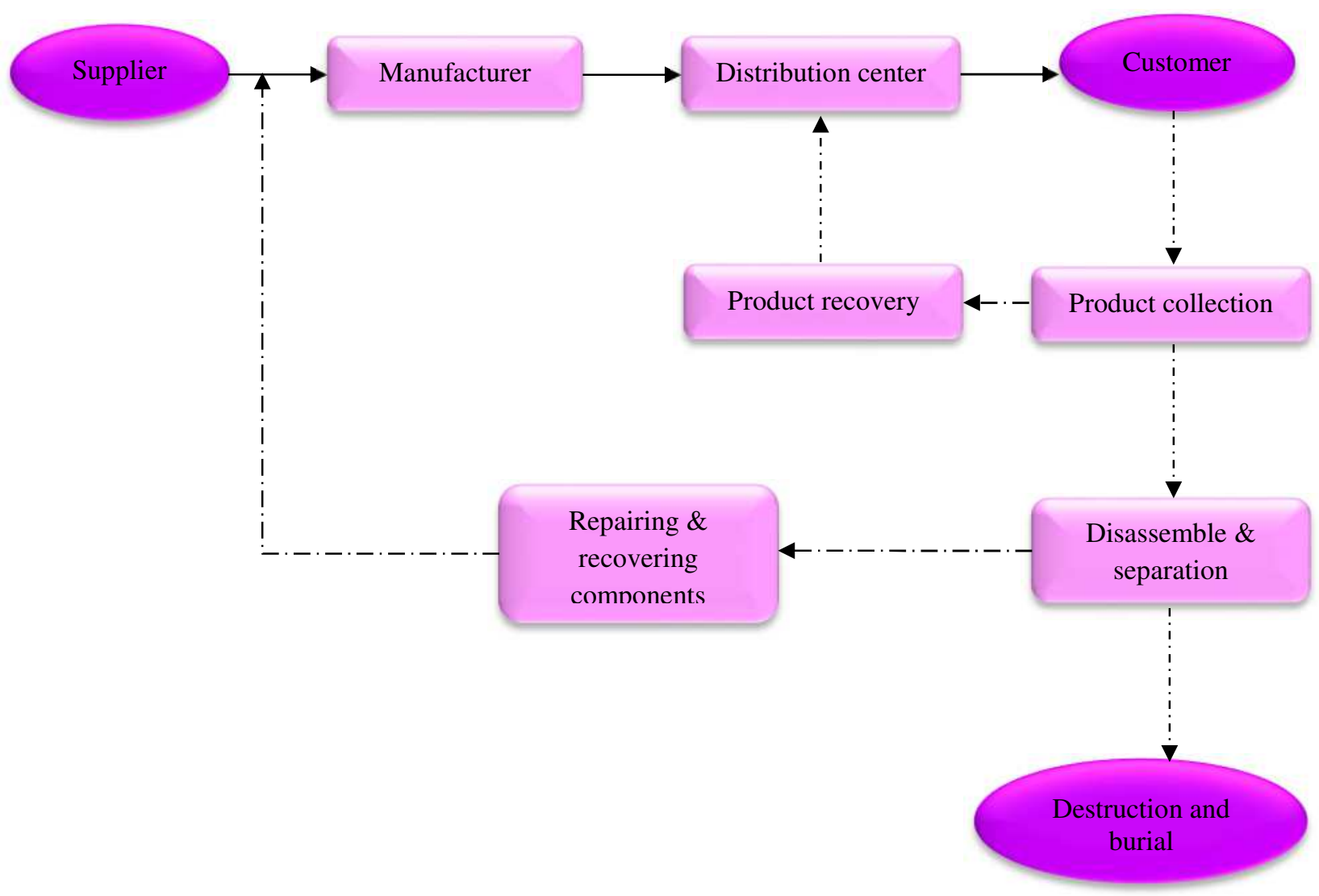

Figure 1. Closed-loop supply chain network with multiple manufacturers.

89 In the present research, the issue of service level and the possibility of shortage and other related 90 parameters and variables in the multi-period closed-loop supply chain network are discussed for 91 the first time. Therefore, discussing, modeling, and solving the closed-loop supply chain problem 92 considering the specific service level to demand, as well as considering the cost of not satisfying 93 the total amount of demand in the cost objective function is one of the contributions of this 94 research.

95 This research has been compiled in 6 sections. The second section deals with the literature review. 96 In the third section, the mathematical model is presented. Fourth section describes the solution 97 algorithm and in the fifth section, the computational results are presented and finally the conclusion 98 will be presented in sixth section. 


\section{Literature review}

100

101

102

103

104

105

106

107

108

109

110

111

112

113

114

115

116

117

118

119

120

121

122

123

124

125

126

127

128

129

Meng et al. (2016) developed a simulation-based hierarchical particle swarm optimization algorithm to solve a multi-criteria production-distribution program. Their integrated program included three objectives of minimizing all costs, including normal labor costs, overtime, outsourcing, inventory maintenance, shortage, recruitment, expulsion, and distribution costs, reducing the work level changes and minimizing inefficiency of work levels. Below are the levels of work. They validated their proposed algorithm with a zero/one hierarchical genetic algorithm. Phuc et al. (2017) investigated the reverse logistics of salvage cars. In their model, the objective functions were fuzzy, and the parameters were deterministic. The problem included four fuzzy objectives: minimizing delivering and transportation costs, minimizing warehouse establishment costs, maximizing reverse service in return flows. The model's results indicated a 15 percent reduction in total system costs. Zheng et al. (2017) formulated a multi-objective linear programming model for optimizing the operations of integrated logistics, reverse logistics, and returned products in a given supply chain. Factors such as the return of used products and subsidies by government agencies were considered in the formulation of the model. Considering the model as decentralized and incomplete information was one of the innovations of this research. Habibi et al. (2017) designed a three-level supply chain, while simultaneously examining the total cost and disassembling effects of different commodities. Their model was a single-product and singleperiod research, including manufacturers, distribution centers and customers. After defining the model using linearization methods, the optimal solution of the problem was obtained by employing an interactive method. In this study, tactical decisions on the selection of transportation system were also considered. Li et al. (2017) examined the supply chain network, including suppliers, factories, and distribution centers. Decisions to be made in this network included setting up the factories and distribution centers, the amount of production and the volume of products. The objective function was defined as minimization of costs. To solve this model, genetic algorithm based on spanning tree was used and the validity of this method was measured by comparing it with the traditional method of genetic algorithm. Pedram et al. (2017) presented a multi-period model for maximizing the reverse supply chain profit of recycled tires. In their proposed model, the recycling capacity was set to minimize the total cost. The advantage of this research was considering strategic and tactical decisions simultaneously. The results indicated the appropriate performance of the proposed model. Kim et al. (2018) presented a robust mathematical model for 
reverse supply chain management with uncertain demand. Considering budget constraints and prioritizing suppliers were of the innovations of this research. To verify the validity of the proposed model, robust optimization was used and to deal with the uncertainty of the problem, simulation was used. Sobotka et al. (2017) investigated the reverse supply chain projects of recycled and resilient materials. Considering the cost of repairs was one of the issues addressed in this study. The results of the numerical examples indicated that the increase in the number of recycled materials leads to an increase in the cost of repairs to a certain level. Yu and Solvang (2018) examined the multi-period and multi-product supply chain. Considering the capacity constraints of facilities and resilience in the supply chain were of the strengths of this research. To model this problem, a two-level approach was used, which in the first level, strategic decisions including allocation of capacity, and in the second level operational decisions including the reduction of supply chain costs were made. Mota et al. (2018) explored an integrated and resilient supply chain in the chain stores in Europe. Considering the location of facilities and the prioritization of suppliers were the most important objectives of this research. The use of social, economic, and environmental factors in the constraints made this research different than similar studies.

Flygansvær et al. (2018) presented a mixed-integer non-linear programming model for the design of a direct and reverse integrated logistics network for logistics service providers. Their case study was 102 electronic industry contractors. To deal with the existing uncertainty of the conditions, the characteristics of the problem were determined for each period, and in the next period, the model was again solved for new characteristics. Cheraghalipour et al. (2018) investigated the logistics of physical section of the supply chain, which involved all activities related to the flow of materials and commodities from the stage of providing the raw materials to the production of the final product, including transportation, warehousing, and so on. One of the new trends in logistics management is recycling or reuse of products. In this method, products that reach the end of their useful life will be re-purchased from the final consumer, and once disassembled, reusable components of the product will be recycled in the form of salvage products. Heydari et al. (2018) presented a zero/one two-level mixed integer programming model considering the direct and inverse flow of recycling of components. The problem was formulated as an incapacitated mathematical model. Considering the model as decentralized and solving it with a heuristic method were of the innovations of this research. 
Eydi et al. (2020) proposed a multi-period multi-echelon forward and reverse supply chain network for product distribution and collection with transportation mode selection. In addition, they formulated a new mixed-integer nonlinear programming model for their problem based on different levels of facility capacities with the maximum profit objective function. Finally, a genetic algorithm was used to solve their model. Antucheviciene et al. (2020) developed sustainable reverse supply chain planning under uncertainty. Their main aims were to maximize the total profit of operation, minimize adverse environmental effects, and maximize customer and supplier service levels. Then, scenario-based robust planning was used to tackle uncertain parameters. To solve their model, non-dominated sorting genetic algorithm II was employed. Finally, they provided actual data from a case study of the steel industry in Iran. Gao and Cao, (2020) provided a new sustainable reverse logistics supply chain network by reconstructing the existing facilities into hybrid processing facilities. They presented a multi-objective scenario-based optimization model to maximize the expected total monetary profits, minimize the expected total carbon emission costs, and maximize the expected total created job opportunities. They used the weighted-sum and augmented-constraint approaches to solve their model. Eventually, a real case study in the tire industry was considered to demonstrate the performance of their model. Sajedi et al. (2020) introduced a two-objective probable mixed integer programming for the design of a closed-loop supply chain. In their model, the reverse flow was considered along with the direct flow as well as strategic decisions along with tactical decisions. Consideration demand as uncertain was one of the innovations of this research. The results indicated a reduction of 8 percent in the costs of the system.

Shadkam, (2021) designed a complex integer linear programming model for an integrated direct logistics and reverse logistic network design considering waste management. Their main aims were to minimize the costs related to the fixed costs, material flow costs, and the costs of building potential centers. Eventually, their model was solved utilizing the cuckoo optimization algorithm. Parast et al. (2021) formulated a bi-objective mixed-integer linear programming model to design a green forward and reverse supply chain under uncertainty. They provided a new locationinventory-routing problem with simultaneous pickup and delivery, scheduling of vehicles, and time window. Their main goals were to minimize total costs and lost demands simultaneously. Moreover, an approach according to the fuzzy theory was presented to cope with uncertain 
parameters. Finally, they considered a real case study to show the performance and efficiency of their model.

\section{Demand forecasting}

Demand plays a crucial role when designing an efficient supply chain network. Indeed, the main part of each supply chain network is to have the reasonable estimation for demand. In this way, this study has utilized the Auto-Regressive Integrated Moving Average (ARIMA) to forecast the number of products demands. On the other hand, knowing the good estimation of demand can help us to know the real costs of the designed network as well as responding to the customers' needs in a proper time. The general equation of ARIMA is brought in Eq. (1) as follows.

$$
\hat{Y}_{t}=\mu+\phi_{1} \cdot Y_{t-1}+\phi_{1} \cdot Y_{t-1}+\ldots+\phi_{1} \cdot Y_{t-1}-\theta_{1} \cdot e_{t-1}-\ldots-\theta_{q} \cdot e_{t-q}
$$

To forecast the demand, we have used the demand dataset between year 2017 and 2020 which is shown in Fig. 2. As we can see, there is NO seasonality patterns for the period that we have investigated our data for products. Therefore, utilizing ARIMA model can help us to have good prediction based on our dataset.

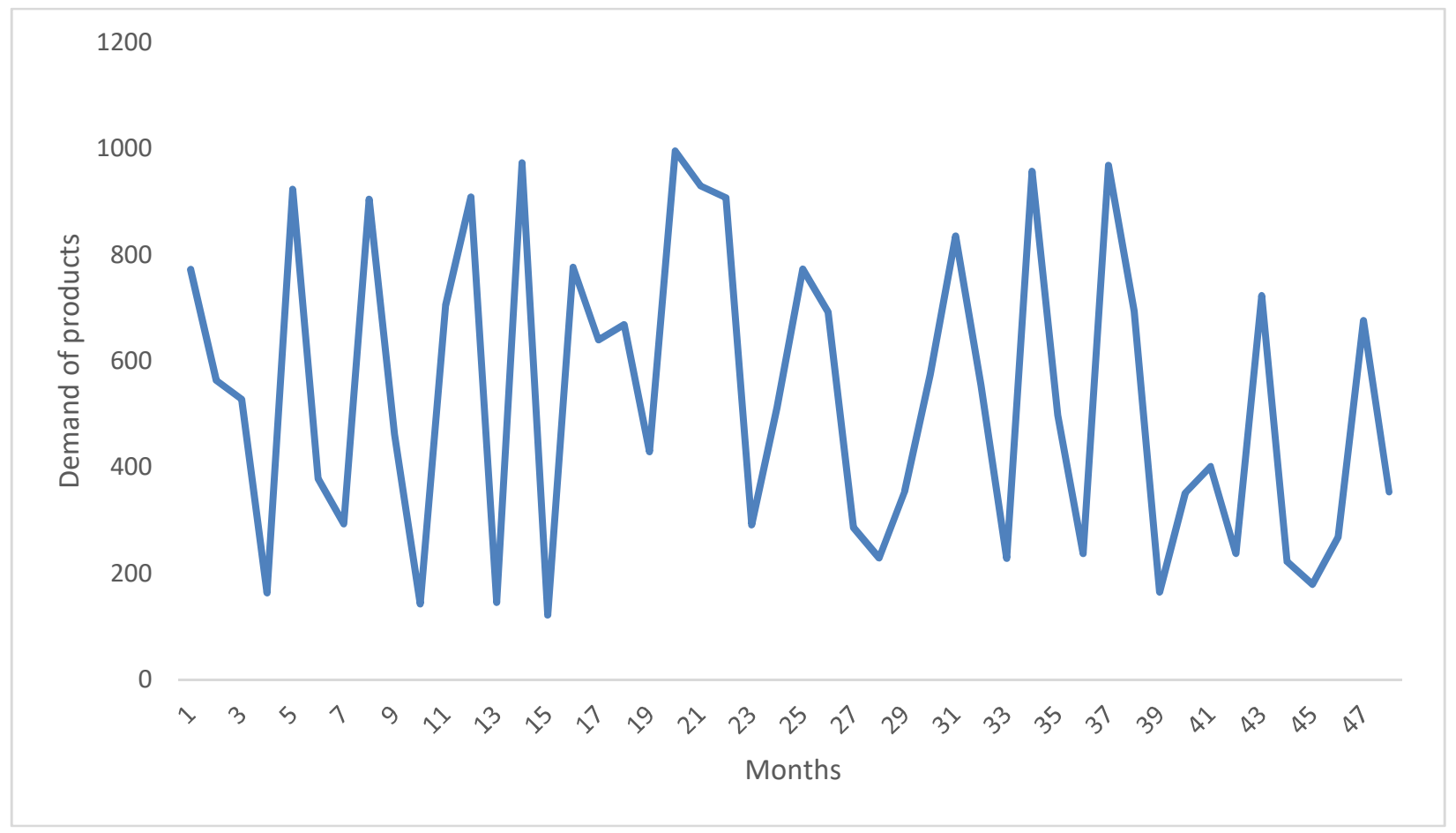


207 Based on Fig. 2, it is clearly visible that the trend of demand of products show the smoot line that 208 is constant from one period to another period (month). Furthermore, the forecasting of demand has 209 been brought in Table 1. As we can see, the demand is predicted for year 2021 based on ARIMA 210 timer series model. So, in this table, we have:

Table 1. Forecasting demands for year 2021 (12 months).

\begin{tabular}{|l|c|c|c|c|c|c|c|c|c|c|c|c|}
\hline Month & 1 & 2 & 3 & 4 & 5 & 6 & 7 & 8 & 9 & 10 & 11 & 12 \\
\hline Demand & 526 & 502 & 645 & 697 & 723 & 576 & 518 & 599 & 464 & 520 & 575 & 608 \\
\hline
\end{tabular}

212 4. Problem statement

213 The objective of the proposed model is to identify the optimal number of products and components

214 in each section of the network through minimizing the total costs of the system and optimizing the 215 number of transporting products in the system. Also, reducing the production costs and using an 216 appropriate producer with lower production costs are other objectives of this model. Indeed, this 217 model aims to determine the allocation of orders to the factories according to the optimal amount 218 of product and customer demand.

219 By proposing this mathematical model, this study has some assumptions which are as follows:

220 - The mathematical model assumed to be multi-period.

221 - Recovered components will be taken to factory warehouse after rebuilding to be distributed to 222 the network.

223 - Shortage has been considered in the model and is allowed.

224 - The transportation system of factories has two states: first, the factories trucks have been used 225 for shipping products in the network. Second, the transportation companies are utilized for having 226 some alternatives to the model to decrease the total costs of transportation in the system. 
228 Symbols used in the mathematical model of this research are as follows:

$229 \quad i:$ index of components $(i \in \mathrm{I})$

$230 j$ : index of products $(j \in J)$

$231 \quad k:$ index of suppliers $(k \in K)$

$232 m$ : index of manufacturers $(m \in M)$

$233 n$ : index of distribution centers $(n \in N)$

$234 \quad l$ : index of recycling and recovery units of components $(l \in I)$

$235 q$ : index of customers $(q \in Q)$

$236 \alpha$ : index of factories' vehicles $(\alpha \in V)$

$237 \alpha^{\prime}$ : index of rental cars of transportation companies $\left(\alpha^{\prime} \in V^{\prime}\right)$

$238 t$ : index of periods

239 Subsets:

$240 J_{j}$ :the set of products that have the component $\mathrm{i}$

241 Model parameters

242 Input parameters include:

$243 S_{j m}$ :Sales price of each unit of the product $\mathrm{j}$ by the manufacturer $\mathrm{m}$

$244 C_{j m}$ :the final production cost of each unit of the product $\mathrm{j}$ by the manufacturer $\mathrm{m}$

$245 \gamma_{q t}$ :the service level of customer $\mathrm{q}$ in period $\mathrm{t}$

$246 D_{j q t}$ :Demand for the product $\mathrm{j}$ by the customer $\mathrm{q}$ in period $\mathrm{t}$

$247 d_{j}$ :Disassembly cost for separation of product $\mathrm{j}$

$248 f_{i}$ :the separation cost of component $\mathrm{i}$

$249 h_{i}$ :destruction or burial cost of component i

$250 o_{i l}$ :the cost of recovering the component $\mathrm{i}$ at the recovery center 1 
$251 r_{i k}$ :the purchase price of component $\mathrm{i}$ that is supplied through the supplier $\mathrm{k}$.

$252 C o_{j}$ :the collection cost of product $\mathrm{j}$

$253 O_{j}^{\prime}$ :the recovery cost of product $\mathrm{j}$

$254 G_{l t}$ :the maximum capacity of recovery center 1 in period $\mathrm{t}$

255 Cap1 $1_{\mathrm{t}}$ : maximum capacity of the product recovery unit in period $\mathrm{t}$

256 Cap2t: maximum capacity of disassembly and separation unit in period $\mathrm{t}$

$257 B_{k}$ :maximum capacity of supplier k

$258 v_{n}$ :maximum capacity of distribution center $\mathrm{n}$

$259 H_{j t}$ :maximum return percentage of product $\mathrm{j}$ in period $\mathrm{t}$

$260 O_{i t}$ :maximum percentage of component $\mathrm{i}$ that is usable in period $\mathrm{t}$

$261 A_{m}$ :maximum capacity of factory $\mathrm{m}$

$262 O_{j}^{\prime \prime}$ :maximum percentage of returned product $\mathrm{j}$ that is recoverable

$263 q_{i j t}$ :The number of components i required to produce a unit of product $\mathrm{j}$ in period $\mathrm{t}$

$264 \operatorname{Trs}_{i k m}$ :The transportation cost of the component $\mathrm{i}$ from the supplier $\mathrm{k}$ to the producer $\mathrm{m}$

$265 \operatorname{Trr}_{j q}$ :The transportation cost of product $\mathrm{j}$ from customer $\mathrm{q}$ to the product collection unit

$266 T r_{j m n \alpha}^{\prime}$ :The transportation cost of the product $\mathrm{j}$ from the factory $\mathrm{m}$ to the distribution center $\mathrm{n}$ by

267 the truck $\alpha$ (owned by the factory $\mathrm{m}$ )

$268 \operatorname{Tr}_{j m n \alpha^{\prime}}^{\prime \prime}$ The transportation cost of the product $\mathrm{j}$ from the factory $\mathrm{m}$ to the distribution center $\mathrm{n}$ by

269 the truck $\alpha^{\prime}$ (owned by the transportation companies)

$270 \operatorname{Trd}_{j n q}:$ The transportation cost of product $\mathrm{j}$ from distribution center $\mathrm{n}$ to customer $\mathrm{q}$

$271 \operatorname{Tr} \omega_{j}:$ The transportation cost of the product $\mathrm{j}$ from the product collection unit to the product 272 recovery unit. 
$273 \operatorname{Trf}_{j n}$ :The transportation cost of the product $\mathrm{j}$ from the product recovery unit to distribution 274 center $n$.

$275 \operatorname{Tra}_{j}$ :The transportation cost of the product $\mathrm{j}$ from the collection unit to disassembly and 276 separation unit

$277 \operatorname{Tr}_{i l}$ :The transportation cost of the component i from disassembly and separation unit to the 278 component recovery center 1

$279 \operatorname{Trc}_{i l m}$ :The transportation cost of the component $\mathrm{i}$ from recovery center 1 to the manufacturer $\mathrm{m}$ $280 \mathrm{Sco}_{j}$ :The cost of not meeting the demand for the product $\mathrm{j}$

$281 \quad \operatorname{Cap3}_{\alpha t}$ :Maximum number of trucks $\alpha$ in period $\mathrm{t}$

$282 \operatorname{Cap}_{\alpha^{\prime} t}$ :Maximum number of trucks $\alpha^{\prime}$ belonging to the transportation company in period $\mathrm{t}$ - Decision variables:

$284 P_{j m n t}:$ The number of products j produced by the manufacturer $\mathrm{m}$ and sent to the distribution 285 center $\mathrm{n}$ in the period $\mathrm{t}$.

$286 \operatorname{Crp}_{j q t}$ :The number of products $\mathrm{j}$ returned by the customer $\mathrm{q}$ in period $\mathrm{t}$.

$287 Q_{i k m t}$ :The number of components i to be supplied by the supplier k and sent to the manufacturer $288 \mathrm{~m}$ in period $\mathrm{t}$.

$289 w_{j}$ :The number of recoverable products $\mathrm{j}$ brought from the collection unit to be recovered.

$290 T_{i l t}$ :The number of components i disassembled by the disassembly unit and sent to the 291 component recovery center 1 in period $t$.

$292 X_{i l m t}$ :The number of components $\mathrm{i}$ that should be rebuilt by the recovery unit 1 and sent to the 293 manufacturer $\mathrm{m}$ in period $\mathrm{t}$.

$294 V_{i}^{\prime}$ :The number of components i that should be destroyed.

$295 R_{j t}^{\prime}$ :The number of products $\mathrm{j}$ collected to be sent to the disassembly segment in period $\mathrm{t}$.

$296 Y_{j n t}^{\prime}$ :The number of recovered products $\mathrm{j}$ sent to the warehouse of the distribution center $\mathrm{n}$ in 297 period t. 
$298 Y_{\text {jnqt }}$ :The number of products $\mathrm{j}$ sent from the distribution center $\mathrm{n}$ to the customer $\mathrm{q}$ in period $\mathrm{t}$.

$299 n h l_{j q t}$ :The number of product $\mathrm{j}$ shortages for customer $\mathrm{q}$ in period $\mathrm{t}$.

$300 X_{j m n \alpha t}^{\prime}$ :The number of products $\mathrm{j}$ sent by the truck $\alpha$ from the manufacturer $\mathrm{m}$ to the distributor $\mathrm{n}$ 301 in period $\mathrm{t}$.

$302 X_{j m n \alpha^{\prime} t}^{\prime \prime}$ :The number of products j sent by the truck $\alpha^{\prime}$ (owned by the transportation companies) 303 from the manufacturer $m$ to the distributor $n$ in period $t$.

$$
\begin{aligned}
& \text { Min c }=\sum_{m} \sum_{k} \sum_{i} r_{i k} \cdot Q_{i k m t}+\sum_{q} \sum_{j} C o_{j} \cdot C r p_{j q t}+\sum_{j} O_{j}^{\prime} \cdot W_{j}+\sum_{j} d_{j} \cdot R_{j t}^{\prime} \\
& +\sum_{n} \sum_{m} \sum_{j} C_{j m} . P_{j m n}+\sum_{i} h_{i} V_{i}^{\prime}+\sum_{m} \sum_{l} \sum_{i} o_{i l} . X_{i l m t}+\sum_{l} \sum_{i} f_{i} \cdot T_{i l t} \\
& \begin{array}{l}
\quad+\sum_{\alpha} \sum_{n} \sum_{m} \sum_{j} X_{j m n \alpha t}^{\prime} \cdot \operatorname{Tr}_{j m n \alpha}^{\prime}+\sum_{m} \sum_{k} \sum_{i} Q_{i k m t} \operatorname{Trs}_{i k m} \\
+\sum_{\alpha^{\prime}} \sum_{n} \sum_{m} \sum_{j} X_{j m n \alpha^{\prime}}^{\prime \prime} \operatorname{Tr}_{j m n \alpha^{\prime}}^{\prime \prime} \\
+\sum_{j}^{\alpha_{j}} R_{j t}^{\prime} \cdot \operatorname{Tra}_{j}+\sum_{n} \sum_{j} Y_{j n t}^{\prime} \cdot \operatorname{Trf}_{j n}+\sum_{j} W_{j} \operatorname{Tr} \omega_{j}+\sum_{q} \sum_{j} \operatorname{Crp}_{j q t} \cdot \operatorname{Tr}_{j q}+\sum_{q} \sum_{n} \sum_{j} Y_{j n q t} \cdot \operatorname{Tr} d_{j n q}
\end{array} \\
& +\sum_{m} \sum_{l} \sum_{i} X_{i l m t} \cdot \operatorname{Trc}_{i l m}+\sum_{q} \sum_{j} S_{j q t} . s c o_{j}+\sum_{l} \sum_{i} T_{i l t} \cdot \operatorname{Tr} b_{i l}
\end{aligned}
$$

304 The objective function includes minimizing the total cost of the system which is shown by 305 equation (2).

\section{- Model constraints:}

$$
\begin{array}{lc}
\sum_{m \in M} X_{i l m t}=T_{i l t} & \forall i, l, t \\
W_{j}=O_{j}^{\prime \prime} \sum_{q \in Q} C p_{j q t} & \forall j, t \\
R_{j t}^{\prime}=\left(1-O_{j}^{\prime \prime}\right) \sum_{q \in Q} C r p_{j q t} & \forall j, t \\
\sum_{q \in Q} Y_{j n q t}=\sum_{m \in M} P_{j m n t}+Y_{j n t}^{\prime} & \forall j, n, t \\
\sum_{n \in N} Y_{j n t}^{\prime}=W_{j} & \forall j, t \\
C r p_{j q t}=\sum_{n \in N} H_{j t} Y_{j n q t} & \forall j, q, t
\end{array}
$$




$$
\begin{array}{ll}
D_{j q t} \cdot \gamma_{q t}=\sum_{n \in N} Y_{j n q t}+n h l_{j q t} & \forall j, q, t \\
\sum_{l \in L} T_{i l t}=O_{i t} \sum_{j \in J_{i}} q_{i j} \cdot R_{j t}^{\prime} & \forall i, t \\
V_{i}^{\prime}=\left(1-O_{i t}\right) \sum_{j \in J_{i}} q_{i j} \cdot R_{j t}^{\prime} & \forall i, t \\
\sum_{i \in I} \sum_{m \in M} Q_{i k m t} \leq B_{k} & \forall k, t \\
\sum_{\alpha \in \alpha_{m}} X_{j m n \alpha t}^{\prime}+\sum_{\alpha^{\prime}} X_{j m n \alpha^{\prime} t}^{\prime \prime}=P_{j m n t} & \forall j, m, n, t \\
\sum_{j \in J} \sum_{n \in N} P_{j m n t} \leq A_{m} & \forall m, t \\
\sum_{j \in J} \sum_{q \in Q} Y_{j n q t} \leq v_{n} & \forall n, t \\
\sum_{j \in J} \sum_{n \in N} Y_{j n t}^{\prime} \leq C a p 1_{t} & \forall t \\
\sum_{i \in l} \sum_{l \in L} T_{i l t} \leq C a p 2_{t} & \forall t \\
\sum_{i \in l} \sum_{m \in M} X_{i l m t} \leq G_{l t} & \forall l, t \\
\sum_{j \in J} \sum_{m \in M} \sum_{n \in N} X_{j m n \alpha t}^{\prime} \leq C a p 3 & \forall \alpha, t \\
\sum_{j \in J} \sum_{m \in M} \sum_{n \in N} X_{j m n \alpha^{\prime} t}^{\prime \prime} \leq C a p 4 & \forall \alpha^{\prime}, t \\
\sum_{n \in N} \sum_{j \in J_{i}} q_{i j} \cdot P_{j m n t} \leq \sum_{l \in L} X_{i l m t}+\sum_{k \in K} Q_{i k m t} & \forall i, m, t \\
P_{j m n t}, C r p_{j q t}, Q_{i k n t}, W_{j}, T_{i l t}, X_{i l m t}, V_{i}^{\prime}, R_{j t}^{\prime}, Y_{j n t}^{\prime}, Y_{j n q t}, n h l_{j q t}, X_{j m n \alpha t}^{\prime}, X_{j m n \alpha^{\prime} t}^{\prime \prime} \geq 0 &
\end{array}
$$

308 Constraint (3) states that the number of disassembled components is equal to the number of 309 components recovered by the component recovery centers. Constraint (4) indicates that the usable 310 products are equal to a percentage of returned products. Constraint (5) indicates that unusable 311 products are equal to a percentage of returned products. Generally, the constraints (4) and (5) show 312 the percentage of the products recovered by recovery centers and the percentage of products 313 collected to be sent to the separation and disassembly units. Constraint (6) states that the number 314 of products sent to customers is equal to the sum of recovered products and produced products. 315 Constraint (7) indicates that the number of usable collected products is equal to the number of 316 recovered products. Constraint (8) shows that returned products are equal to a percentage of 
317 products purchased by customers. Constraint (9) ensures that the minimum demand should be met, 318 and the shortage should be minimized. Constraints (10) and (11) specify the number of usable and 319 unusable components in the disassembly unit and determine the percentage of waste and usable 320 components. Constraint (12) specifies the maximum capacity of supplier k. Constraint (13) states 321 that the number of produced components sent to distribution centers is equal to the number of 322 products sent by factory and rental trucks. The Constraints (14) and (15) show, respectively, the 323 capacity constraints of the factories and the distribution centers. Constraints (16) and (17) indicate, 324 respectively, the capacity constraints of the product recovery unit and disassembly section. 325 Constraint (18) shows the capacity constraints for component recovery units. Constraints (19) and 326 (20) also indicate capacity constraints of containers. Constraint (21) states that the number of 327 produced components is equal to the total number of recovered components and purchased 328 components from suppliers. Finally, constraint (22) shows the nature of decision variables in the 329 model.

\section{Solving algorithm}

331 In this study, the exact solution algorithm is used to solve the model in small and medium scale 332 and the Genetic Algorithm (GA) is applied to solve the model in large scale. The flowchart of the 333 GA which displays an overview of how the algorithm is executed, is shown in Fig. 4. 


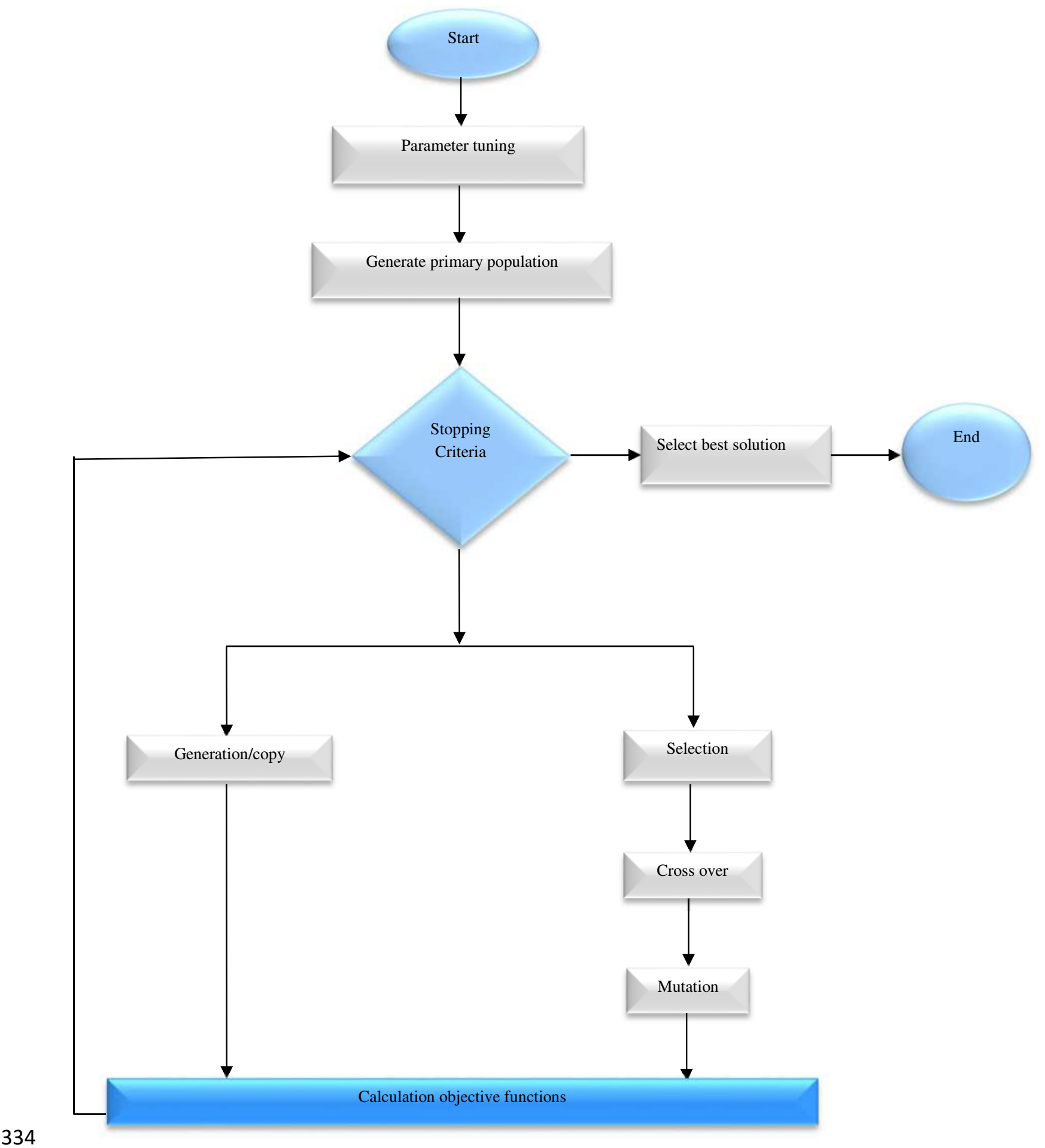

Figure 4. Flowchart of the genetic algorithm 


\subsection{Display of the chromosome}

The first step after determining the technique used to convert each solution to a chromosome is to create an initial population of chromosomes. At this stage, the initial solution is usually generated randomly. Here, for example, the chromosome of the variable $S_{j q t}$ is shown in Fig. (5) as follows:

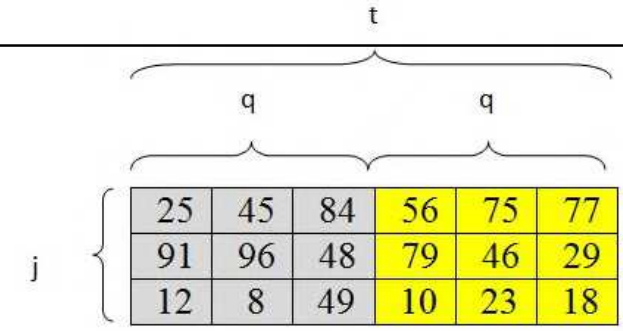

\section{Figure 5. chromosome representation}

The numbers inside each gene indicate the amount of shortage in the related period.

\subsection{Genetic operations}

Genetic operations imitate the inherited gene transfer process for the creation of new children in each generation. An important part in the genetic algorithm is the creation of new chromosomes called children through some of the old chromosomes called parents. In general, this operation is performed by two major operators: mutation operator and crossover operator.

\subsection{Crossover operators}

There are the operators that select one or more points from two or more solutions and change their values. These operators consider a solution and exchange some locations of the solution with other solutions to create new solutions. These operators are called crossover operators. In fact, on the remaining chromosomes of the initial population, a crossover is performed. Here in Figure 6, a two-point crossover is used. 


\begin{tabular}{|c|c|c|c|c|c|}
\hline 25 & 45 & 84 & 56 & 75 & 77 \\
\hline 91 & 96 & 48 & 79 & 46 & 29 \\
\hline 12 & 8 & 49 & 10 & 23 & 18 \\
\hline 56 & 23 & 43 & 97 & 84 & 62 \\
\hline 44 & 56 & 25 & 18 & 91 & 18 \\
\hline 31 & 75 & 11 & 19 & 47 & 78 \\
\hline 25 & 45 & 43 & 97 & 75 & 77 \\
\hline 91 & 96 & 25 & 18 & 46 & 29 \\
\hline 12 & 8 & 11 & 19 & 23 & 18 \\
\hline 56 & 23 & 84 & 56 & 84 & 62 \\
\hline 44 & 56 & 48 & 79 & 91 & 18 \\
\hline 31 & 75 & 49 & 10 & 47 & 78 \\
\hline
\end{tabular}

Figure 6. Two-point crossover operator

\subsection{Mutation operators}

There are the operators that select one or more genes from a chromosome and change their values. In these operators, one or more locations of a character string with a specific length are considered and the values of the characters in those locations are changed. In this type of operators, the solution information is used to create another answer. This change may be too little or too much, and too little or too much information is used based on the amount of change. In other words, the more the changes are, the solution will be more random; and this randomness is useful for entering the new genetic materials into the population. When the population converges towards a particular solution, the probability of a mutation must be increased to prevent this, and vice versa, if the population has non-identical solutions, the probability of mutation must be reduced. Here, for a mutation operator, a row is randomly selected and reversed.

\begin{tabular}{|c|c|c|c|c|c|}
\hline 25 & 45 & 84 & 56 & 75 & 77 \\
\hline 91 & 96 & 48 & 79 & 46 & 29 \\
\hline 12 & & 49 & 10 & 23 & 18 \\
\hline 25 & 45 & 84 & 56 & 75 & T \\
\hline 29 & 46 & 79 & 48 & 96 & 91 \\
\hline 12 & 8 & 49 & 10 & 23 & 18 \\
\hline
\end{tabular}

Figure 7. Mutation operator 


\subsection{Stopping criteria}

371 After the birth of children and generating a new generation and calculating its fitness function,

372 there is a need for a criterion to end the algorithm that we refer to some of the most common ones.

373

374

375

376

377

378

379

380

381

382

383

384

385

- Implementation of the program is often carried out for a predetermined number of generations. For example, at the beginning of the program, the number of generations is 50 for repetition.

- Sometimes, computing time is considered as a criterion to stop the algorithm.

- Sometimes this criterion is based on the extent of the dispersion of genes within the population.

In the problem-solving approach of some algorithms, time, and in some others, maximum number of generations is used.

For statistical analysis, we use the least significant difference method (LSD) to find significant differences (Chouhan et al. 2021, Arani et al. 2021, Dehdari Ebrahimi, et al. 2017, Ahmed et al. 2020). Figure 6 shows the output of the LSD method using the MINITAB statistical software. According to the results, it can be concluded that the genetic algorithm has a better performance in a discrete state than the rest of the algorithms.

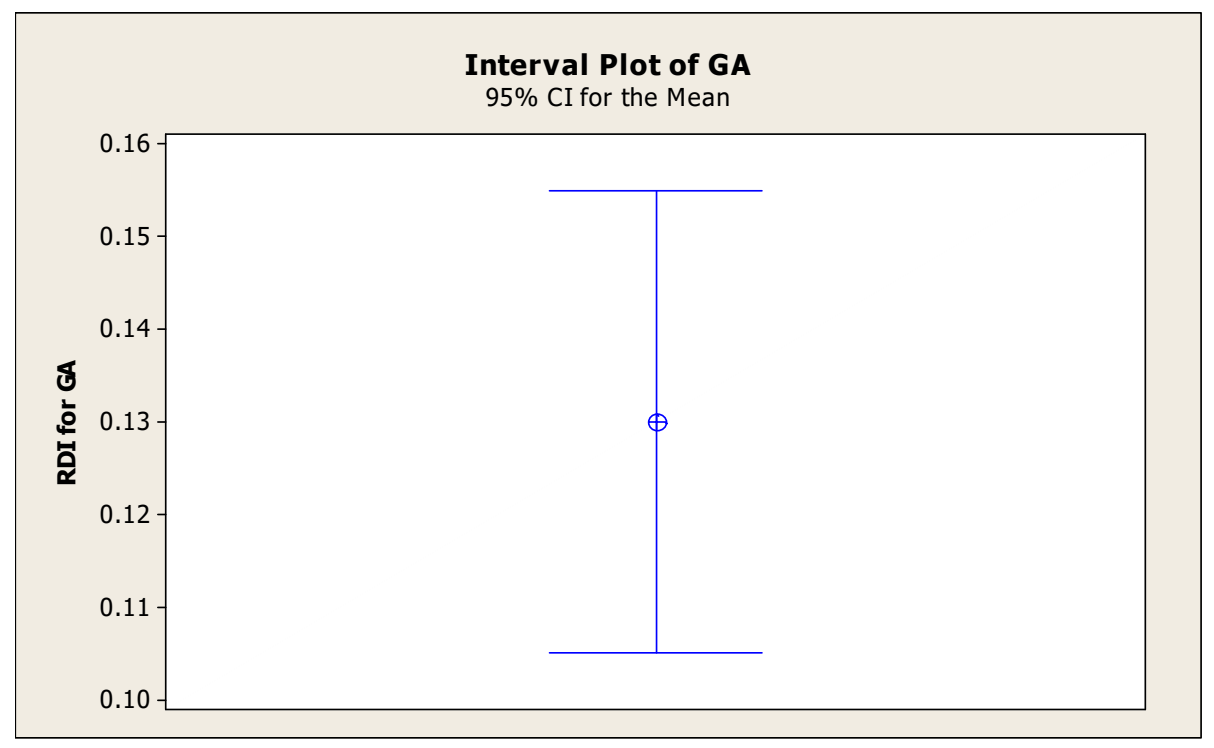

Figure 8. 95\% confidence interval for the RDI objective function 

After determining the optimal parameters of the algorithms, for evaluating the performance of the meta-heuristic method the exact solution is considered. Due to the high solution time of the exact methods for large scale problems, problem solving is not possible with the GAMS software, so the meta-heuristic methods has been applied in this study. According to the complexity of solving the mathematical model by increasing the scale of the problem, calculating the optimal amount is very difficult. Therefore, the judgment criterion is the solution of the GAMS software, which is a solution close to optimal. Table 2 shows the scale of the test problems in small level.

Table 2. Small scale selected problems

\begin{tabular}{lcccccc}
\hline $\mathbf{N}$ & Supplier no & $\begin{array}{c}\text { Factory } \\
\text { no }\end{array}$ & $\begin{array}{c}\text { Distribution } \\
\text { center no }\end{array}$ & $\begin{array}{c}\text { Customer } \\
\text { no }\end{array}$ & Product no & $\begin{array}{c}\text { factor } \\
\text { multiplication }\end{array}$ \\
\hline $\mathbf{1}$ & 1 & 2 & 2 & 3 & 1 & 12 \\
$\mathbf{2}$ & 1 & 2 & 3 & 3 & 2 & 36 \\
$\mathbf{3}$ & 2 & 2 & 2 & 4 & 2 & 64 \\
$\mathbf{4}$ & 2 & 3 & 3 & 4 & 2 & 144 \\
$\mathbf{5}$ & 3 & 2 & 3 & 5 & 3 & 270 \\
\hline
\end{tabular}

Table 3 shows the results of the model solution in small and medium scale. The first column of the table is the problem number. The first five problems are in small scale and the next five are in medium scale. According to the results obtained from the problem-solving algorithms and GAMS software, we found that in small scale and in most cases, the solution obtained from algorithms was better than the solution proposed by GAMS software which shows the efficiency of the algorithms. By increasing the scale of the problem, GAMS software cannot solve the problem at a reasonable time, but other algorithms give a near optimal solution at a very appropriate time. As shown in Table 3, the average error is 0.7 percent. Also, the problem-solving time of the exact

407 algorithm is much lower and has a lower rate. So, given the above explanations, the genetic algorithm can be trusted to solve large-scale problems.

Table 3. Results of model solving in small and medium scale

\begin{tabular}{cccccc}
\hline \multirow{2}{*}{ No } & \multicolumn{2}{c}{ Gams } & \multicolumn{2}{c}{ Genetic } & Error \% \\
\cline { 2 - 6 } & $f_{1}$ & Time(s) & $f_{1}$ & Time(s) & $f_{1}$ \\
$\mathbf{1}$ & 8150.2 & 1 & 8150.2 & 1 & 0 \\
$\mathbf{2}$ & 8342.4 & 50 & 8343.5 & 5 & 0.01 \\
\hline
\end{tabular}




\begin{tabular}{cccccc}
\hline $\mathbf{3}$ & 8609.4 & 88 & 8701.1 & 7 & 1 \\
$\mathbf{4}$ & 8972.5 & 112 & 9036.1 & 12 & 0.7 \\
$\mathbf{5}$ & 9385.0 & 215 & 9432.0 & 13 & 0.4 \\
$\mathbf{6}$ & 12321.1 & 1018 & 12511.6 & 27 & 1.5 \\
$\mathbf{7}$ & 14159.2 & 3293 & 14160.8 & 30 & 0 \\
$\mathbf{8}$ & 16774.9 & 3892 & 17023.3 & 37 & 1.4 \\
$\mathbf{9}$ & 17819.7 & 5826 & 18005.5 & 50 & 1.0 \\
$\mathbf{1 0}$ & 19218.8 & 8797 & 19588.8 & 63 & 1.8 \\
Ave & $\mathbf{1 2 3 7 5 . 3}$ & $\mathbf{2 3 2 9 . 2}$ & $\mathbf{1 2 4 9 5 . 2}$ & $\mathbf{2 4 . 5}$ & $\mathbf{0 . 7}$ \\
\hline
\end{tabular}

410

411 To solve the problem in large scale, there are 30 product types, 35 customers, 2 periods, 4 suppliers,

4122 manufacturers, 2 distributors and 3 recycling centers. Table 4 shows the results of a large-scale

413 model solution. This table shows the shortage of product $\mathrm{j}$ for the customer $\mathrm{q}$ in the period $\mathrm{t}$ which

414 is the result of the variablenh $\boldsymbol{l}_{\boldsymbol{j q t}}$.

415

416

417

418

419

420

421

422

423

424

425

426

427

428

429 Table 5 shows the number of returned products $\mathrm{j}$ in period $\mathrm{t}$ by customer $\mathrm{q}$. This table is the result 430 of the variablecrp $\boldsymbol{p}_{\text {jpt }}$.

Table 4. Shortage level of product $\mathrm{j}$ for customer $\mathrm{q}$ in period $\mathrm{t}$

\begin{tabular}{|c|c|c|c|c|c|c|c|}
\hline$n h l_{i a t}$ & & $n h l_{i a t}$ & & $n h l_{i a t}$ & & $n h l_{i a t}$ & \\
\hline$n h l_{1,13,1}$ & 208 & $n h l_{16,6,1}$ & 736 & $n h l_{1,13,2}$ & 569 & $n h l_{17,33,2}$ & 807 \\
\hline$n h l_{1,5,1}$ & 720 & $n h l_{17,5,1}$ & 786 & $n h l_{2,27,2}$ & 439 & $n h l_{18,2,2}$ & 377 \\
\hline$n h l_{1,22,1}$ & 746 & $n h l_{17,7,1}$ & 718 & $n h l_{3,19,2}$ & 261 & $n h l_{19,22,2}$ & 596 \\
\hline$n h l_{2,28,1}$ & 488 & $n h l_{18,10,1}$ & 745 & $n h l_{4,11,2}$ & 207 & $n h l_{19,24,2}$ & 190 \\
\hline$n h l_{3,5,1}$ & 669 & $n h l_{19,12,1}$ & 181 & $n h l_{5,30,2}$ & 137 & $n h l_{20,23,2}$ & 616 \\
\hline$n h l_{3,14,1}$ & 529 & $n h l_{20,13,1}$ & 411 & $n h l_{6,23,2}$ & 724 & $n h l_{20,8,2}$ & 496 \\
\hline$n h l_{4,11,1}$ & 737 & $n h l_{21,32,1}$ & 397 & $n h l_{7,9,2}$ & 811 & $n h l_{20,29,2}$ & 528 \\
\hline$n h l_{5,34,1}$ & 585 & $n h l_{21,16,1}$ & 365 & $n h l_{7,6,2}$ & 203 & $n h l_{21,33,2}$ & 778 \\
\hline$n h l_{6,29,1}$ & 688 & $n h l_{22,20,1}$ & 280 & $n h l_{7,7,2}$ & 299 & $n h l_{22,34,2}$ & 378 \\
\hline$n h l_{6,30,1}$ & 822 & $n h l_{23,29,1}$ & 788 & $n h l_{8,35,2}$ & 154 & $n h l_{23,4,2}$ & 264 \\
\hline$n h l_{7,25,1}$ & 139 & $n h l_{24,19,1}$ & 746 & $n h l_{9,1,2}$ & 726 & $n h l_{24,26,2}$ & 304 \\
\hline$n h l_{8,8,1}$ & 145 & $n h l_{24,2,1}$ & 277 & $n h l_{10,10,2}$ & 822 & $n h l_{25,28,2}$ & 831 \\
\hline$n h l_{9,32,1}$ & 434 & $n h l_{25,32,1}$ & 499 & $n h l_{10,12,2}$ & 726 & $n h l_{26,32,2}$ & 310 \\
\hline$n h l_{10,9,1}$ & 591 & $n h l_{25,17,1}$ & 183 & $n h l_{11,25,2}$ & 700 & $n h l_{27,28,2}$ & 219 \\
\hline$n h l_{11,2,1}$ & 182 & $n h l_{26,18,1}$ & 154 & $n h l_{11,18,2}$ & 787 & $n h l_{27,14,2}$ & 696 \\
\hline$n h l_{12,35,1}$ & 520 & $n h l_{26,21,1}$ & 665 & $n h l_{11,17,2}$ & 442 & $n h l_{28,17,2}$ & 176 \\
\hline$n h l_{13,1,1}$ & 857 & $n h l_{26,26,1}$ & 690 & $n h l_{12,10,2}$ & 851 & $n h l_{29,28,2}$ & 364 \\
\hline$n h l_{13,33,1}$ & 718 & $n h l_{27,24,1}$ & 835 & $n h l_{13,16,2}$ & 341 & $n h l_{30,19,2}$ & 100 \\
\hline$n h l_{14,27,1}$ & 223 & $n h l_{28,21,1}$ & 453 & $n h l_{14,21,2}$ & 847 & $n h l_{30,21,2}$ & 140 \\
\hline$n h l_{15,25,1}$ & 424 & $n h l_{29,23,1}$ & 136 & $n h l_{15,3,2}$ & 420 & & \\
\hline$n h l_{15,4,1}$ & 804 & $n h l_{30,6,1}$ & 435 & $n h l_{16,5,2}$ & 464 & & \\
\hline
\end{tabular}


Table 5. The number of returned products $\mathrm{j}$ in period $\mathrm{t}$ by the customer $\mathrm{q}$

\begin{tabular}{|c|c|c|c|c|c|c|c|}
\hline$c r p_{j p t}$ & & $c r p_{j q t}$ & & $c r p_{j q t}$ & & $c r p_{j q t}$ & \\
\hline$c r p_{1,15,1}$ & 464 & $c r p_{16,5,1}$ & 671 & $c r p_{1,13,2}$ & 108 & $c r p_{16,6,2}$ & 836 \\
\hline$c r p_{2,2,1}$ & 693 & $\operatorname{crp}_{17,2,1}$ & 592 & $c r p_{2,10,2}$ & 566 & $c r p_{17,4,2}$ & 489 \\
\hline $\operatorname{crp}_{3,13,1}$ & 344 & $c r p_{18,14,1}$ & 720 & $c r p_{3,19,2}$ & 376 & $c r p_{18,18,2}$ & 347 \\
\hline $\operatorname{crp}_{4,9,1}$ & 520 & $c r p_{19,11,1}$ & 230 & $c r p_{4,1,2}$ & 702 & $c r p_{19,11,2}$ & 579 \\
\hline $\operatorname{crp}_{5,9,1}$ & 258 & $c r p_{20,11,1}$ & 415 & $c r p_{5,11,2}$ & 407 & $c r p_{20,8,2}$ & 359 \\
\hline $\operatorname{crp}_{6,20,1}$ & 165 & $c r p_{20,4,1}$ & 470 & $c r p_{6,20,2}$ & 757 & $c r p_{20,9,2}$ & 862 \\
\hline $\operatorname{crp}_{6,15,1}$ & 203 & $c r p_{21,7,1}$ & 493 & $c r p_{6,15,2}$ & 350 & $c r p_{21,9,2}$ & 615 \\
\hline $\operatorname{crp}_{6,15,1}$ & 533 & $c r p_{21,7,1}$ & 896 & $c r p_{7,7,2}$ & 445 & $\operatorname{crp}_{22,16,2}$ & 478 \\
\hline$c r p_{7,1,1}$ & 221 & $c r p_{22,12,1}$ & 137 & $c r p_{8,12,2}$ & 625 & $c r p_{23,14,2}$ & 431 \\
\hline$c r p_{8,10,1}$ & 235 & $c r p_{23,16,1}$ & 261 & $c r p_{9,19,2}$ & 655 & $c r p_{24,5,2}$ & 363 \\
\hline $\operatorname{crp}_{9,19,1}$ & 117 & $c r p_{24,8,1}$ & 250 & $c r p_{10,6,2}$ & 237 & $\operatorname{crp}_{25,8,2}$ & 787 \\
\hline$c r p_{10,6,1}$ & 108 & $c r p_{25,8,1}$ & 192 & $c r p_{10,11,2}$ & 466 & $c r p_{26,17,2}$ & 717 \\
\hline$c r p_{11,18,1}$ & 163 & $c r p_{26,17,1}$ & 342 & $c r p_{11,17,2}$ & 107 & $\operatorname{crp}_{27,3,2}$ & 376 \\
\hline$c r p_{12,3,1}$ & 863 & $c r p_{27,3,1}$ & 791 & $c r p_{12,3,2}$ & 321 & $c r p_{28,3,2}$ & 161 \\
\hline$c r p_{13,2,1}$ & 712 & $c r p_{28,20,1}$ & 495 & $c r p_{13,2,2}$ & 534 & $c r p_{29,13,2}$ & 633 \\
\hline $\operatorname{crp}_{14,3,1}$ & 164 & $c r p_{29,13,1}$ & 196 & $c r p_{14,3,2}$ & 836 & $c r p_{30,15,2}$ & 196 \\
\hline $\operatorname{crp}_{15,12,1}$ & 144 & $c r p_{30,15,1}$ & 895 & $c r p_{15,12,2}$ & 183 & ${ }^{\prime} r p_{30,17,2}$ & 582 \\
\hline
\end{tabular}

442

443 Figure 9 shows the value of objective functions calculated by the genetic algorithm in terms of

444 various parameters. As can be seen, the calculated values have a reasonable convergence, so, we 445 can also rely on the results of a large-scale model solution that can also be trusted. 
454 Figure 11 shows the relationship between the service levels in each period with the value of the 455

Figure 10 shows the relationship between the rates of returned products in each period with the value of the objective function. It is obvious that increasing the rate of return, could increase the cost. For example, an increase in the rate of return up to 94 units have resulted in a cost of 434,418 $\$$ and increasing it to 100 units lead to result in a cost of 482,687 units.

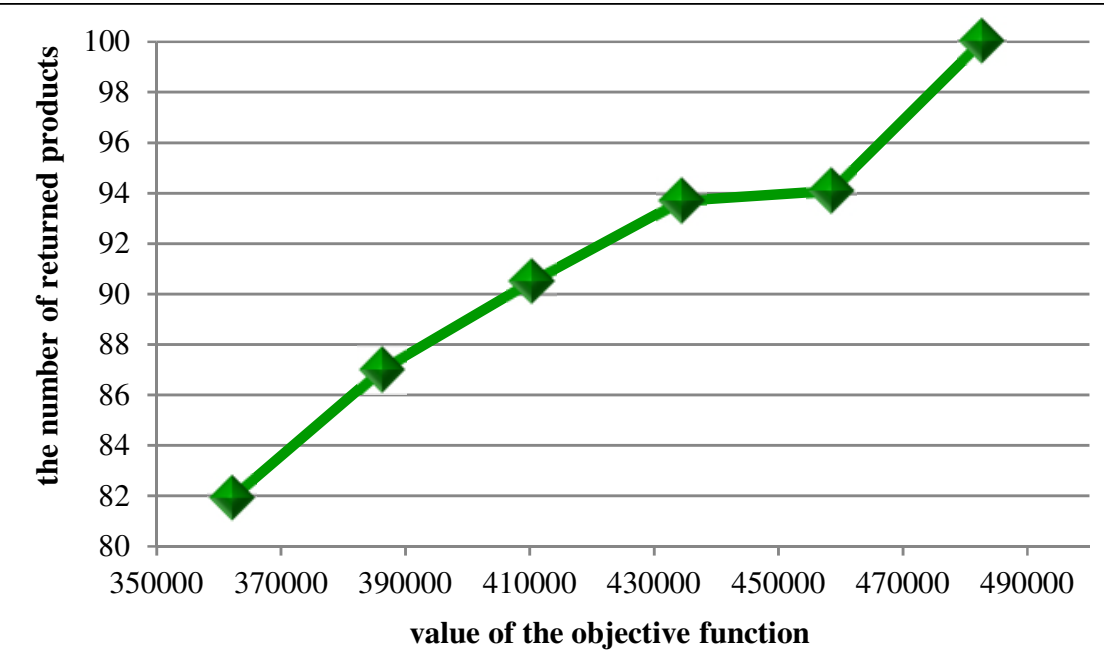

Figure 10. Changes in the amount of costs based on returned products objective function. As obvious, increasing service level have reduced the costs. For example, an

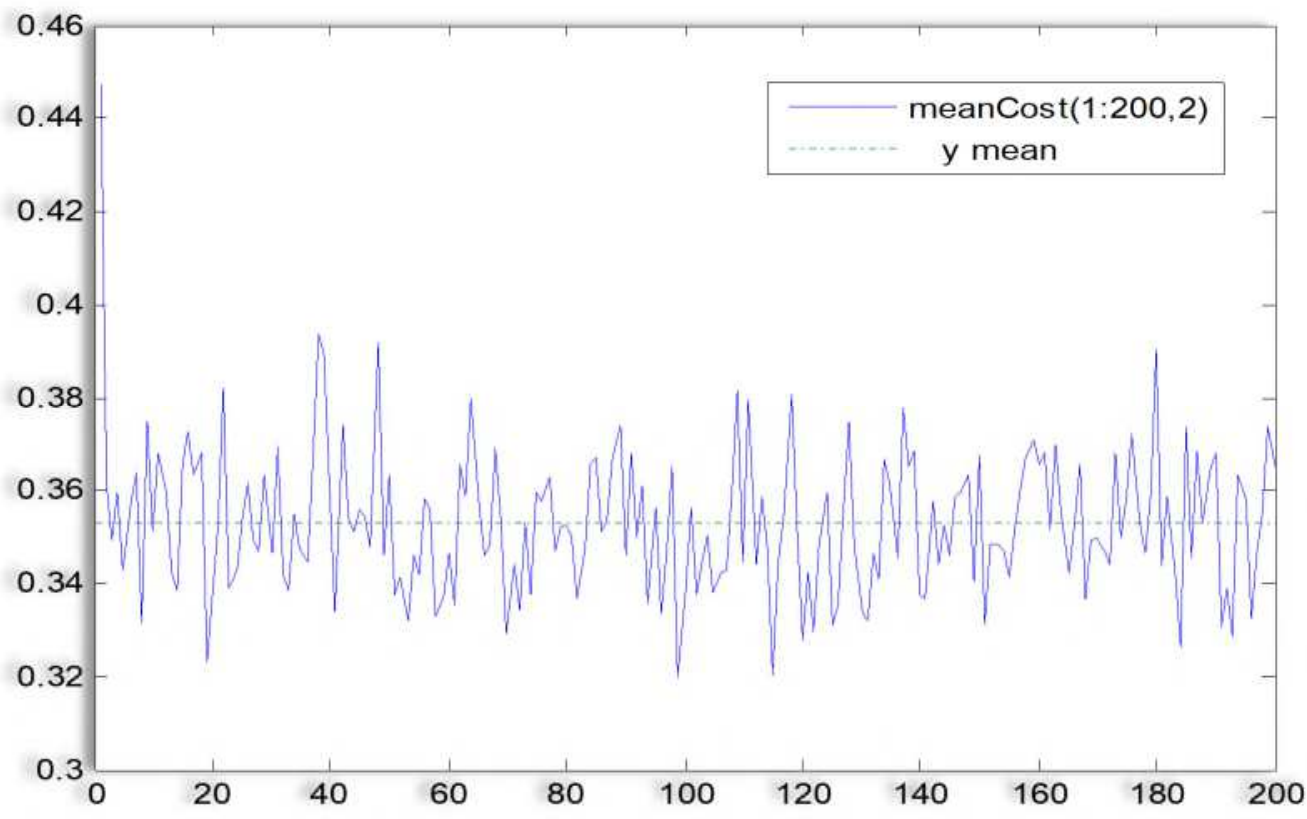

Figure 9. Convergence of the genetic algorithm 
456 increase in service level up to 1.7 units have resulted in a cost of 490,318 units and an increase up 457 to 2 units lead to result in a cost of 438,789 units.

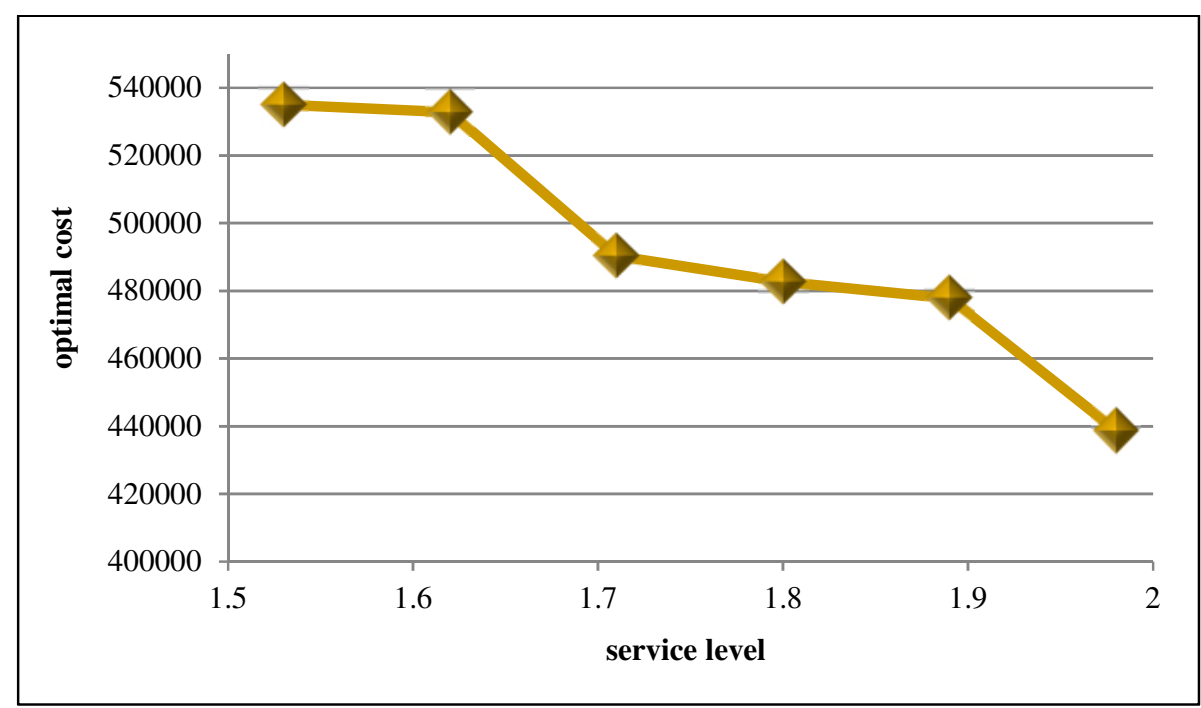

Figure 11. Changes in the amount of costs based on service level

\section{Conclusion}

To achieve efficient supply chain management, organizations need to design an efficient transportation network. In general, the design of the supply chain network is considered as one of the most important issues in the field of optimization. In this research, a closed-loop supply chain network was studied and modeled in the form of mixed integer programming. The objective of this study was to minimize the total costs considering a specific service level to demand, as well as considering the cost of not satisfying the total amount of demand. Therefore, demand points have a certain amount of demand that its certain level must be supplied and, in proportion to the non-satisfied amount of demand, the related cost is added to the objective function. Also, since this problem has a high computational complexity, it is categorized as NP-hard. So, the genetic algorithm was used to solve the proposed model. The results of the sensitivity analysis indicated that increasing the rate of return could increase the cost.

Several aspects can be considered for future research which are as follows:

- Considering the capacity constraint for inventory storage in factories warehouses and distribution centers

- Considering the facility location problem for factories and distribution centers 
- Considering a variety of sales policies such as gradual discounts and incremental discounts for production costs

- Considering the single-source state to meet demands, it means that each customer is only connected with one distribution center.

\section{References}

- $\quad$ Ahmed, M. M., Iqbal, S. S., Priyanka, T. J., Arani, M., Momenitabar, M., \& Billal, M. M. (2020, August). An Environmentally Sustainable Closed-Loop Supply Chain Network Design under Uncertainty: Application of Optimization. In International Online Conference on Intelligent Decision Science (pp. 343358). Springer, Cham.

- Ali, I., Modibbo, U. M., Chauhan, J., \& Meraj, M. (2021). An integrated multi-objective optimization modelling for sustainable development goals of India. Environment, Development and Sustainability, 23(3), 3811-3831.

- $\quad$ Almaraj, I. I., \& Trafalis, T. B. (2019). An integrated multi-echelon robust closed-loop supply chain under imperfect quality production. International Journal of Production Economics, 218, 212-227.

- $\quad$ Antucheviciene, J., Jafarnejad, A., Amoozad Mahdiraji, H., Razavi Hajiagha, S. H., \& Kargar, A. (2020). Robust multi-objective sustainable reverse supply chain planning: An application in the steel industry. Symmetry, 12(4), 594.

- $\quad$ Arani, M., Chan, Y., Liu, X., \& Momenitabar, M. (2021). A lateral resupply blood supply chain network design under uncertainties. Applied Mathematical Modelling, 93, 165-187.

- $\quad$ Chan, F. T., Jha, A., \& Tiwari, M. K. (2016). Bi-objective optimization of three echelon supply chain involving truck selection and loading using NSGA-II with heuristics algorithm. Applied soft computing, 38, 978-987.

- $\quad$ Cheraghalipour, A., Paydar, M. M., \& Hajiaghaei-Keshteli, M. (2018). A bi-objective optimization for citrus closed-loop supply chain using Pareto-based algorithms. Applied Soft Computing, 69, 33-59.

- Chouhan, V. K., Khan, S. H., \& Hajiaghaei-Keshteli, M. (2021). Metaheuristic approaches to design and address multi-echelon sugarcane closed-loop supply chain network. Soft Computing, 25(16), 1137711404.

- $\quad$ Dehdari Ebrahimi, Z., \& Momeni Tabar, M. (2017). Design of mathematical modeling in a green supply chain network by collection centers in the environment. Environmental Energy and Economic Research, 1(2), 153-162.

- $\quad$ Eydi, A., Fazayeli, S., \& Ghafouri, H. (2020). Multi-period configuration of forward and reverse integrated supply chain networks through transport mode. Scientia Iranica, 27(2), 935-955.

- Flygansvær, B., Dahlstrom, R., \& Nygaard, A. (2018). Exploring the pursuit of sustainability in reverse supply chains for electronics. Journal of Cleaner Production, 189, 472-484.

- Gao, X., \& Cao, C. (2020). A novel multi-objective scenario-based optimization model for sustainable reverse logistics supply chain network redesign considering facility reconstruction. Journal of Cleaner Production, 270, 122405.

- $\quad$ Ghasemi, P., Khalili-Damghani, K., Hafezolkotob, A., \& Raissi, S. (2017). A decentralized supply chain planning model: a case study of hardboard industry. The International Journal of Advanced Manufacturing Technology, 93(9), 3813-3836.

- Goodarzian, F., Kumar, V., \& Ghasemi, P. (2021b). A set of efficient heuristics and meta-heuristics to solve a multi-objective pharmaceutical supply chain network. Computers \& Industrial Engineering, 158, 107389.

- Goodarzian, F., Taleizadeh, A. A., Ghasemi, P., \& Abraham, A. (2021a). An integrated sustainable medical supply chain network during COVID-19. Engineering Applications of Artificial Intelligence, 100, 104188.

- $\quad$ Habibi, M. K., Battaïa, O., Cung, V. D., \& Dolgui, A. (2017). Collection-disassembly problem in reverse supply chain. International Journal of Production Economics, 183, 334-344. 
- $\quad$ Hassanpour, A., Bagherinejad, J., \& Bashiri, M. (2019). A robust leader-follower approach for closed loop supply chain network design considering returns quality levels. Computers \& Industrial Engineering, 136, 293-304.

- Heydari, J., Govindan, K., \& Sadeghi, R. (2018). Reverse supply chain coordination under stochastic remanufacturing capacity. International Journal of Production Economics, 202, 1-11.

- $\quad$ Kim, J., Do Chung, B., Kang, Y., \& Jeong, B. (2018). Robust optimization model for closed-loop supply chain planning under reverse logistics flow and demand uncertainty. Journal of cleaner production, 196, 1314-1328.

- $\quad$ Li, J., Wang, Z., Jiang, B., \& Kim, T. (2017). Coordination strategies in a three-echelon reverse supply chain for economic and social benefit. Applied Mathematical Modelling, 49, 599-611.

- Margolis, J. T., Sullivan, K. M., Mason, S. J., \& Magagnotti, M. (2018). A multi-objective optimization model for designing resilient supply chain networks. International Journal of Production Economics, 204, 174-185.

- Meng, K., Lou, P., Peng, X., \& Prybutok, V. (2016). A hybrid approach for performance evaluation and optimized selection of recoverable end-of-life products in the reverse supply chain. Computers \& Industrial Engineering, 98, 171-184.

- Modibbo, U. M., Arshad, M., Abdalghani, O., \& Ali, I. (2021). Optimization and estimation in system reliability allocation problem. Reliability Engineering \& System Safety, 212, 107620.

- Modibbo, U. M., Umar, I., Mijinyawa, M., \& Hafisu, R. (2019). Genetic Algorithm for Solving University Timetabling Problem. Amity Journal of Computational Sciences (AJCS), 3(1), 43-50.

- Mohtashami, Z., Aghsami, A., \& Jolai, F. (2020). A green closed loop supply chain design using queuing system for reducing environmental impact and energy consumption. Journal of cleaner production, 242, 118452.

- Mosallanezhad, B., Chouhan, V. K., Paydar, M. M., \& Hajiaghaei-Keshteli, M. (2021). Disaster relief supply chain design for personal protection equipment during the COVID-19 pandemic. Applied Soft Computing, 112, 107809.

- Mota, B., Gomes, M. I., Carvalho, A., \& Barbosa-Povoa, A. P. (2018). Sustainable supply chains: An integrated modeling approach under uncertainty. Omega, 77, 32-57.

- $\quad$ Parast, Z. Z. D., Haleh, H., Darestani, S. A., \& Amin-Tahmasbi, H. (2021). Green reverse supply chain network design considering location-routing-inventory decisions with simultaneous pickup and delivery. Environmental Science and Pollution Research, 1-22.

- Pedram, A., Yusoff, N. B., Udoncy, O. E., Mahat, A. B., Pedram, P., \& Babalola, A. (2017). Integrated forward and reverse supply chain: A tire case study. Waste Management, 60, 460-470.

- $\quad$ Phuc, P. N. K., Vincent, F. Y., \& Tsao, Y. C. (2017). Optimizing fuzzy reverse supply chain for end-oflife vehicles. Computers \& Industrial Engineering, 113, 757-765.

- $\quad$ Sajedi, S., Sarfaraz, A. H., Bamdad, S., \& Khalili-Damghani, K. (2020). Designing a Sustainable Reverse Logistics Network Considering the Conditional Value at Risk and Uncertainty of Demand under Different Quality and Market Scenarios. International Journal of Engineering, 33(11), 2252-2271.

- Shadkam, E. (2021). Cuckoo optimization algorithm in reverse logistics: A network design for COVID19 waste management. Waste Management \& Research, 0734242X211003947.

- Sobotka, A., Sagan, J., Baranowska, M., \& Mazur, E. (2017). Management of reverse logistics supply chains in construction projects. Procedia engineering, 208, 151-159.

- Wang, G., \& Gunasekaran, A. (2017). Operations scheduling in reverse supply chains: Identical demand and delivery deadlines. International Journal of Production Economics, 183, 375-381.

- Wu, Z., Kwong, C. K., Aydin, R., \& Tang, J. (2017). A cooperative negotiation embedded NSGA-II for solving an integrated product family and supply chain design problem with remanufacturing consideration. Applied Soft Computing, 57, 19-34.

- $\quad$ Xu, Z., Elomri, A., Pokharel, S., Zhang, Q., Ming, X. G., \& Liu, W. (2017). Global reverse supply chain design for solid waste recycling under uncertainties and carbon emission constraint. Waste management, 64, 358-370.

- Yu, H., \& Solvang, W. D. (2018). Incorporating flexible capacity in the planning of a multi-product multiechelon sustainable reverse logistics network under uncertainty. Journal of cleaner production, 198, 285303.

- Zheng, B., Yang, C., Yang, J., \& Zhang, M. (2017). Pricing, collecting and contract design in a reverse supply chain with incomplete information. Computers \& Industrial Engineering, 111, 109-122. 


\section{Ethical Approval and Competing Interests}

- All authors have participated in (a) conception and design, or analysis and interpretation of the data; (b) drafting the article or revising it critically for important intellectual content; and (c) approval of the final version.

- This manuscript has not been submitted to, nor is under review at, another journal or other publishing venue and has not self-plagiarism

- The authors have no affiliation with any organization with a direct or indirect financial interest in the subject matter discussed in the manuscript

\section{Consent to Participate and Consent to Publish}

Furthermore, we hereby transfer the unlimited rights of publication of the above-mentioned paper in whole to "Environmental science and pollution research". The corresponding author signs for and accepts responsibility for releasing this material on behalf of any and all co-authors. This agreement is to be signed by at least one of the authors who have obtained the assent of the co-author(s) where applicable. After submission of this agreement signed by the corresponding author, changes of authorship or in the order of the authors listed will not be accepted.

Yours Sincerely,

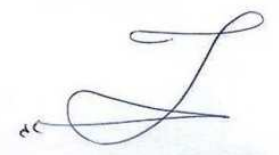

\section{Authors Contributions}

Shahab Safaei: Conceptualization

Peiman Ghasemi: Mathematical Model, Software, Investigation, Methodology.

Fariba Goodarzian: Data curation, Writing- Reviewing and Editing

Mohsen Momenitabar: Data curation, Writing- Reviewing and Editing

\section{Declaration of interests}

The authors declare that they have no known competing financial interests or personal relationships that could have appeared to influence the work reported in this paper.

\section{Funding}

This research received no specific grant from any funding agency in the public, commercial, or not-for-profit sectors. 
511 The data that support the findings of this study are available from the corresponding author, , 512 upon reasonable request 